\title{
Business Retention and Expansion (BRE) Programs: Approaches to BRE Programs ${ }^{1}$
}

Henry M. Cothran²

\section{Introduction}

Communities began to focus on the retention of existing businesses as an economic development strategy in the 1970s when many manufacturing firms began to move in search of reduced operating costs (Blaine, Hudkins, and Taylor, 1999). These programs typically had four broad goals (Kraybill, 1995):

1. Show quick results by immediately addressing and fixing, when possible, urgent problems of local businesses.

2. Describe the local economy by communicating its positive attributes and trends, such as the number of jobs retained and saved.

3. Develop a strategic economic development plan designed to improve the local business climate.

4. Foster local action through the creation of local implementation work groups.

Over time, two broad approaches to implementing BRE programs emerged. In a 1999 presentation at the Ohio Economic Development Course, these two approaches were described as being either "traditional" or "continuous"

(Kraybill, 1995). Today, these types of programs, as well as an almost infinite number of variations, are in operation throughout the United States and Canada. This publication describes the general characteristics of the two approaches and identifies several strengths and weaknesses inherent in each of the approaches.

This publication is the second in a series of ten on establishing Business Retention and Expansion programs. The publications in this series can be found online at the EDIS website at http://edis.ifas.ufl.edu/TOPIC_SERIES_BRE.

\section{Traditional Approach}

The traditional approach is sometimes referred to as the "volunteer" approach because it relies in large part on community volunteers to carry out the program. Developed initially (and separately) by New Jersey Bell Telephone and the Ohio Cooperative Extension Service in the early 1980s, this approach is designed to bring structure to what had heretofore been informal, unstructured efforts that focused on improving public relations between the community and its local firms. Based on research conducted by

1. This is EDIS document FE652, a publication of the Food and Resource Economics Department, Florida Cooperative Extension Service, Institute of Food and Agricultural Sciences, University of Florida, Gainesville, FL. Published September 2006. Please visit the EDIS website at http://edis.ifas.ufl.edu.

2. Henry M. Cothran, Associate In, Food and Resource Economics Department, Florida Cooperative Extension Service, Institute of Food and Agricultural Sciences, University of Florida, Gainesville, FL.

The Institute of Food and Agricultural Sciences (IFAS) is an Equal Opportunity Institution authorized to provide research, educational information and other services only to individuals and institutions that function with non-discrimination with respect to race, creed, color, religion, age, disability, sex, sexual orientation, marital status, national origin, political opinions or affiliations. U.S. Department of Agriculture, Cooperative Extension Service, University of Florida, IFAS, Florida A. \& M. University Cooperative Extension Program, and Boards of County Commissioners Cooperating. Larry Arrington, Dean 
Professors George Morse and Scott Loveridge, this approach was described in a publication titled "Implementing Local Business Retention and Expansion Visitation Programs" that was published by the Northeast Regional Center for Rural Development in 1998. In the ensuing years a number of "how to" manuals, describing minor modifications to the original approach, have also been published. Because the approach was refined and popularized by university faculty working in the Cooperative Extension Service and because the approach relies heavily on community volunteers, the approach is often, although mistakenly, thought of as only a rural economic development program.

General characteristics of the traditional approach have been described as follows (Kraybill, 1995):

- The program is led by a coordinator who works with a leadership team of 10 to 25 business and government leaders as well as concerned citizens who meet over a period of a year and provide guidance for all phases of the program.

- Between 50 and 100 local businesses are selected for visitation.

- Community volunteers conduct face-to-face interviews using a common survey instrument.

- The survey program is conducted every three to five years.

- A portion of the survey is designed to identify the immediate, urgent concerns of the interviewed businesses. These issues are reviewed immediately by members of the program leadership team, and action is taken to provide a rapid respond to the issue.

- Typically, the program uses outside assistance to obtain a survey, train local volunteers to conduct business visits, tabulate and interpret the survey results, and suggest long-term actions to strengthen the local economy. The leadership team chooses which projects it will implement, and develops action plans to implement the projects.
This approach has been, and continues to be, successful in many communities. When followed exactly as described in the literature, it produces both immediate results and a longer-term economic development plan. The use of trained volunteers to collect data from local businesses has several advantages. First, face-to-face data collection always has a higher response rate than mail or telephone surveys. Second, when a sufficient number of volunteers are recruited and trained, the data collection period can be very short, thus decreasing the time lag between the identification of immediate business concerns and the community's response.

Third, using volunteers significantly reduces the cost of data collection. Finally, using volunteers increases a community's awareness of its local businesses and their contribution to a community's economic well-being.

However, this approach has three potential weaknesses. First, this approach typically calls for someone from outside the community to guide each step of the program. That person, often called a BRE consultant, is responsible for obtaining or developing a survey instrument, training the volunteers in survey administration, analyzing data, and writing a report of findings and recommended actions. Relying on outside help may result in a drop-off in participation and implementation once the surveys are completed and the outsider leaves the community. Second, the approach does not envision the development of an ongoing BRE effort beyond the business survey conducted every three to five years. Thus any opportunity to visit other businesses to identify and respond to critical issues, such as plans to close operations, is lost. Third, many, if not most, communities do not initiate another large-scale survey program once the original long-range plan implementation is completed.

\section{The Continuous Approach}

The continuous approach is sometimes referred to as the "paid staff" approach because it relies on local economic development professionals to develop and direct the program. As the name implies, this is an on-going approach to business retention and expansion efforts. Kraybill (1995) described these programs as: 
- Managed by a local economic developer.

- Operating continuously with a limited number of business surveys conducted over the course of a year.

- Businesses are interviewed either via face-to-face or telephone by the local economic developer.

- The economic developer provides rapid response to "quickly fixable" needs identified by the surveyed businesses. In this capacity, the developer acts as a convener or broker between the business and the entity that can address the identified need.

- In some programs, a larger group may be convened to develop an action plan to improve the local business climate.

- The economic developer "narrates" the local economy, based on the on-going business interviews, to the local press, business organizations, elected officials, and the general public.

The continuous approach also has been, and continues to be, successful in many communities. Its principal strength lies in the use of a paid staff who develop and maintain an on-going relationship with those entities providing services to existing businesses. Since the staff is paid to work with existing businesses there will always be some effort to inform the community about the needs and concerns of the existing business community. It can also be argued that the business community has a fixed, and known, point of contact when they have problems or need assistance.

This approach also has limitations. Visiting a limited number of businesses typically shifts the focus to the large employers in the community. Thus the needs and concerns of small or emerging businesses may be overlooked. While a random sample survey allows immediate identification of problems faced by all businesses, the continuous approach would take years to accomplish the same objective. It may also be difficult for economic development professionals to make a case for change in government policy since they may be viewed as putting business interests above community interest. Finally, failing to involve the broader community in economic development through some form of active participation will create or reinforce the belief that economic development is an activity best left to the "professionals" and not something that should be of concern to all members of the community.

\section{Conclusion}

While many of today's programs can be traced to either of the two historical approaches, there is no single right way to implement a local business retention and expansion program. Professionals and volunteers across North America, Australia, New Zealand, and South Africa have modified these approaches to fit the needs and capabilities of the communities in which they live and work, resulting in a range of programs focused on existing businesses. Community efforts range from single-event activities (e.g., annual business appreciation dinners) to professionally-staffed offices offering a full range of training and technical assistance to the existing business community. The type of programs and range of services is limited only by the resources and efforts of the community. As former Director of Research for the Council on Urban Economic Development Alan Gregerman said, "The form that works best ... is a function of many factors, including community size, economic circumstances, local development objectives, and the level of commitment of (the) public and private sectors to economic improvement."

\section{References}

Blaine, Thomas, Stephen Hudkins, and Charles Taylor. 1999. Taking R\&E to the Next Level. http://www.joe.org/joe/1999december/a2.html. Accessed online on September 6, 2006.

Kraybill, D. 1995. Retention and Expansion First. Ohio's Challenge 8(2):4-7 [Department of Agricultural, Environmental, and Development Economics, Ohio State University, Columbus, $\mathrm{OH}]$.

Morse, George W., and Scott Loveridge. 1998. Implementing Local Business Retention and Expansion Visitation Programs. Northeast Regional 
Center for Rural Development, The Pennsylvania

State University, University Park, PA. 